06

\title{
Исследование формирования слоев станната цинка методом рентгеновской фотоэлектронной спектроскопии
}

\author{
(C) С.С. Налимова, ${ }^{1}$ 3.В. Шомахов, ${ }^{2}$ В.А. Мошников, ${ }^{1}$ А.А. Бобков, ${ }^{1}$ А.А. Рябко, ${ }^{1}$ 3.Х. Калажоков ${ }^{2}$ \\ ${ }^{1}$ Санкт-Петербургский государственный электротехнический университет „ЛЭТИ“ им. В.И. Ульянова (Ленина), \\ 197376 Санкт-Петербург, Россия \\ ${ }^{2}$ Кабардино-Балкарский государственный университет им. Х.М. Бербекова, \\ 360004 Нальчик, Россия \\ e-mail: sskarpova@list.ru
}

Поступило в Редакцию 23 июля 2019 г.

В окончательной редакции 19 января 2020 г.

Принято к публикации 27 января 2020 г.

Рассмотрены особенности формирования наноструктур станната цинка, представляющих интерес для сенсорики, солнечной энергетики и проводящей прозрачной электроники. Образцы получены гидротермальным методом с использованием наностержней оксида цинка в качестве шаблона при вариации времени синтеза и исследованы с помощью рентгеновской фотоэлектронной спектроскопии. Показано, что данный метод может быть использован для анализа особенностей образования станната цинка.

Ключевые слова: рентгеновская фотоэлектронная спектроскопия, оксид цинка, станнат цинка, гидротермальный синтез.

DOI: $10.21883 /$ JTF.2020.07.49447.276-19

\section{Введение}

Полупроводниковые адсорбционные датчики в течение многих лет широко используются при решении различных научно-технических задач $[1,2]$. В настоящее время интенсивно развивается несколько направлений создания газочувствительных сенсоров. Одним из направлений является создание сенсоров с низкими значениями рабочей температуры [3-5]. При этом активно анализируются возможности замены нагревателей источниками оптического излучения [6]. Другим направлением является повышение селективности путем создания мультисенсорных систем [7]. Также для увеличения селективности газовых сенсоров используется создание перколяционных кластеров, возникающих на границах зерен оксидов металлов при изменении состава поверхностных фаз $[8,9]$.

Усовершенствование методов оценки кислотно-основных свойств поверхностных адсорбционных центров способствовало развитию материаловедения многокомпонентных систем, в которых в непосредственной близости находятся адсорбционные центры для анализируемого газа, и центры десорбции, в которых после каталитической реакции происходит сублимация продуктов [10]. Развитие этого направления перспективно для улучшения быстродействия сенсоров [11].

Как новый материал для сенсорики, солнечной энергетики и проводящей прозрачной электроники интерес представляет станнат цинка [12-15]. Получение станната цинка осложняется тем, что помимо $\mathrm{ZnSnO}_{3}$ может образовываться $\mathrm{Zn}_{2} \mathrm{SnO}_{4}$, а также возможно протекание реакций распада с образованием гетерогенной системы. В наноструктурированном варианте было показано, что при использовании реакции замещения при взаимодействии наностержней $\mathrm{ZnO}$ со станнатом калия может происходить образование нанопроводов станната цинка [16], однако изменение температурно-временных режимов или $\mathrm{pH}$-среды может приводить к разрушению предварительно созданной системы наностержней $\mathrm{ZnO}$. В настоящее время ощущается острая необходимость развития методик эффективного контроля взаимодействия предварительно сформированной системы нанообъектов $\mathrm{ZnO}$ с прекурсорами, обеспечивающими протекание реакции замещения, и управления значением $\mathrm{pH}$-среды. Кроме концентрации взаимодействующих материалов значительную роль будут играть температурно-временные режимы проведения реакции.

Нами для контроля процессов, протекающих в таких сложных системах, в качестве физического метода была использована рентгеновская фотоэлектронная спектроскопия (РФЭС). Ранее была показана эффективность использования данного метода для анализа влияния содержания кислорода в различных связанных состояниях на поверхности бинарных и смешанных оксидов на их чувствительность к парам этанола [17]. Целью настоящей работы является доказательный анализ необходимости и достаточности использования РФЭС для контроля получения наноструктурированных слоев станната цинка.

\section{Эксперимент}

В качестве исходных материалов были взяты слои, состоящие из ограненных наностержней $\mathrm{ZnO}$, полученных низкотемпературным $\left(85^{\circ} \mathrm{C}\right)$ гидротермальным 

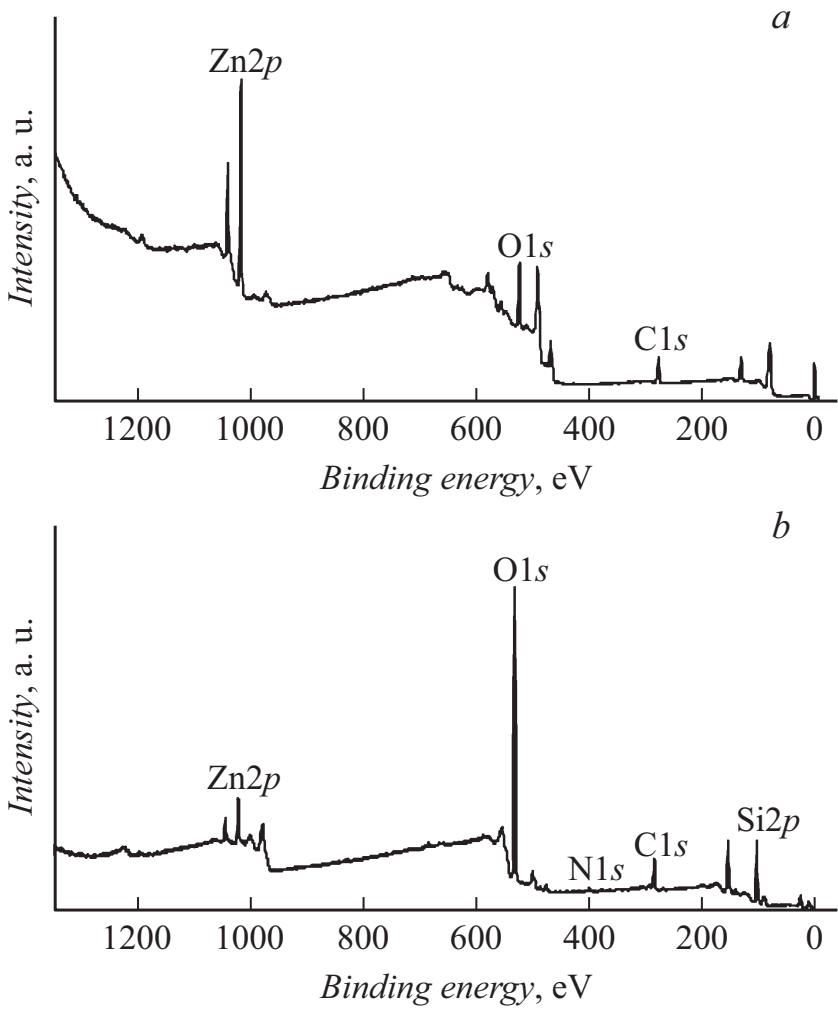

Рис. 1. Обзорные спектры образцов: $a-$ исходные наностержни, $b$ - образец, синтезированный в течение $3 \mathrm{~h}$.

методом на кремниевой подложке с использованием затравочного слоя, сформированного с помощью метода ультразвукового спрей-пиролиза. Низкотемпературный гидротермальный синтез проводился с использованием водного раствора гексаметилентетрамина и нитрата цинка с эквимолярными концентрациями $0.025 \mathrm{~mol} / \mathrm{l}$, a также с добавлением аммиачной воды и полиэтиленимина для подавления нуклеации. Образцы наностержней оксида цинка на кремниевой подложке помещали в водно-спиртовой раствор тригидрата станната калия $\mathrm{K}_{2} \mathrm{SnO}_{3} \cdot 3 \mathrm{H}_{2} \mathrm{O}$ и мочевины $\mathrm{CH}_{4} \mathrm{~N}_{2} \mathrm{O}$. Синтез проводили в автоклаве при $170^{\circ} \mathrm{C}$ при вариации времени синтеза и концентрации прекурсоров. Реакция взаимодействия оксидов цинка с солями олова и образование станната цинка может приводить к формированию различных гетерофазных структур.

Экспериментальные спектры синтезированных композитных образцов и исходных наностержней оксида цинка были получены на рентгеновском фотоэлектронном спектрометре K-Alpha фирмы Thermo Scientific (США). Обзорные спектры, позволяющие определить все присутствующие в образцах элементы, были получены в диапазоне энергий связи от 0 до $1350 \mathrm{eV}$. Спектры отдельных элементов были сняты с целью более точного определения положения пиков. Проведена деконволюция (разложение) спектров остовных уровней кислорода.

\section{Результаты и обсуждение}

Первый тестовый анализ состоял из энергетических спектров исходных наностержней $\mathrm{ZnO}$. Как видно из обзорного спектра (рис. 1,a), на поверхности наностержней присутствуют цинк, кислород и углерод. Наличие пиков углерода во всех образцах свидетельствует об адсорбции на их поверхности углеводородов из окружающей атмосферы. Положения пиков на спектре остовного уровня цинка $(1022.3$ и $1045.3 \mathrm{eV})$ соответствуют заряженному состоянию $\mathrm{Zn}^{2+}$ [18]. Пики на спектре остовного уровня кислорода (рис. 2, $a$ ) соответствуют кислороду кристаллической решетки $(530.8 \mathrm{eV})$ и кислороду поверхностных гидроксильных групп (532.8 eV) [17].
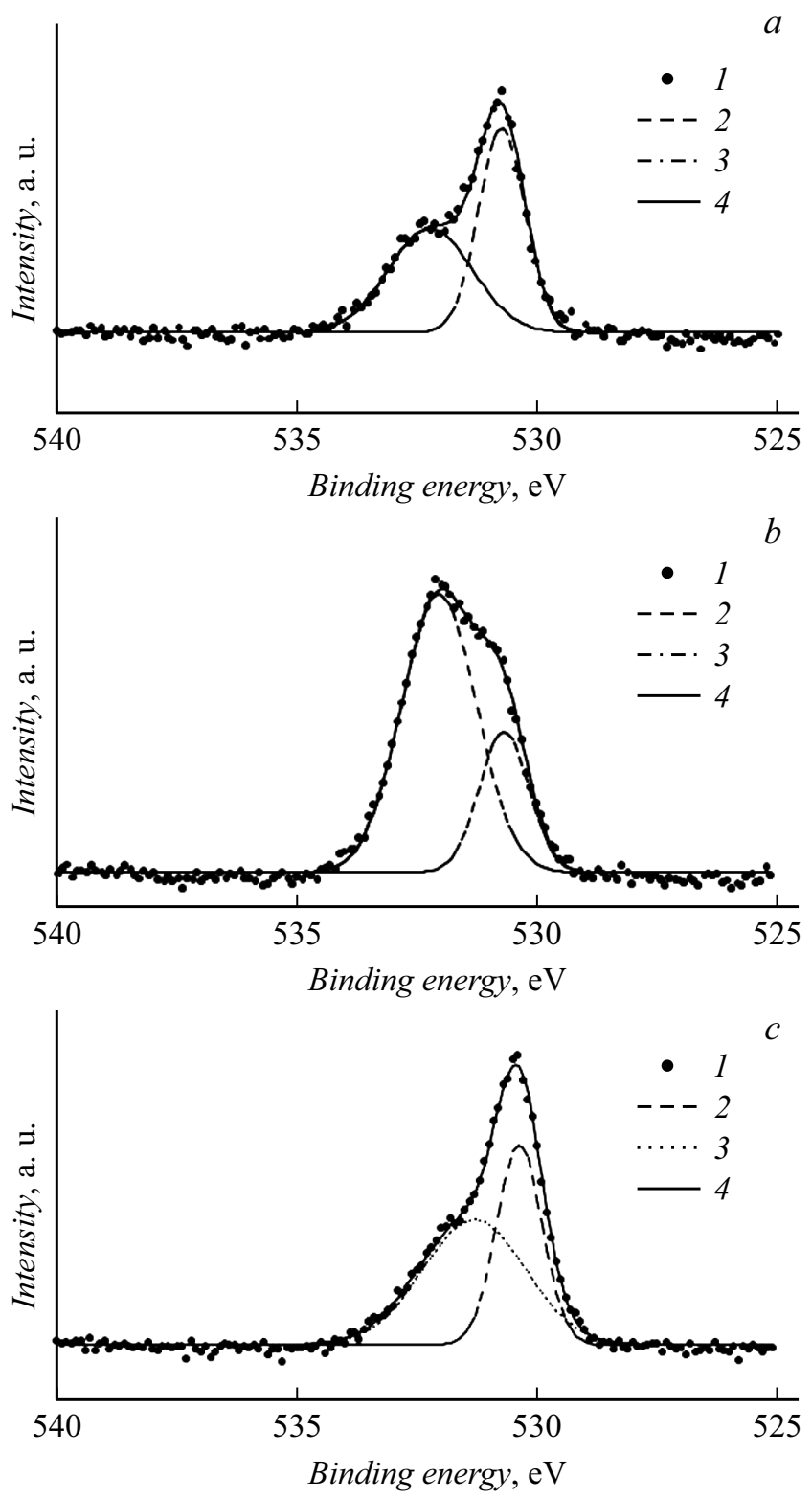

Pис. 2. Спектры остовного уровня кислорода: $a-$ исходные наностержни, $b$ - образец, синтезированный в течение $30 \mathrm{~min}$, $c$ - образец, синтезированный в течение $1 \mathrm{~h}$. 

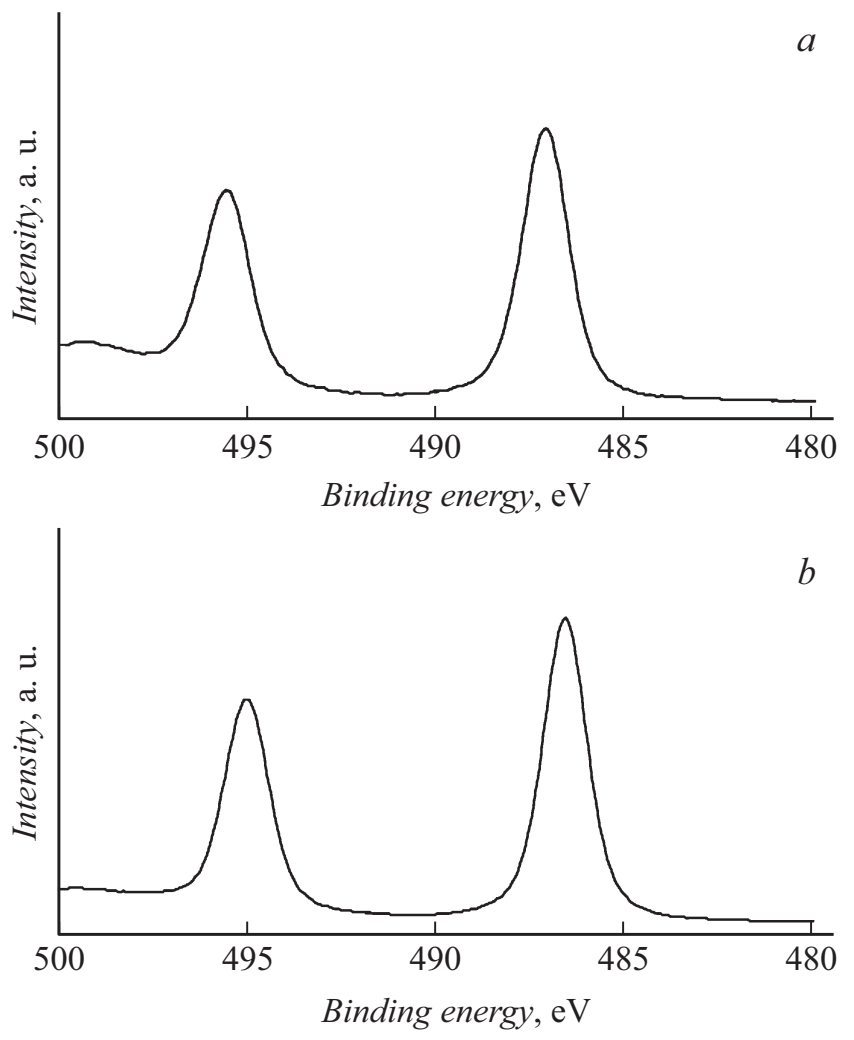

Рис. 3. Спектры остовного уровня олова: $a-$ образец, синтезированный в течение $30 \mathrm{~min}, b-$ образец, синтезированный в течение $1 \mathrm{~h}$.

Второй пример относится к проведению синтеза в течение $30 \mathrm{~min}$ и иллюстрирует моменты, когда процесс замещения практически не происходил. Положение пиков на спектре остовного уровня цинка остается неизменным по сравнению с исходными наностержнями. Наблюдается сдвиг пиков, соответствующих кислороду в форме $\mathrm{O}^{2-}$ и кислороду, входящему в состав поверхностных гидроксильных групп, в сторону меньших энергий связи на 0.1 и $0.3 \mathrm{eV}$ соответственно (рис. $2, b$ ). Пики на спектре остовного уровня олова (495.6 и $487.2 \mathrm{eV}$ ), представленном на рис. $3, a$, соответствуют $\mathrm{Sn}^{2+}$. Присутствие производных $\mathrm{SnO}$ в спектре $\mathrm{Sn} 3 d 5 / 2$ объясняют кислородными вакансиями в кристаллической решетке и уменьшенной концентрацией кислорода на поверхности, более отчетливо проявляющимися после отжига, что приводит к увеличению соотношения интенсивностей пиков $\mathrm{SnO}$ и $\mathrm{SnO}_{2}$ после отжига $\left(450^{\circ} \mathrm{C}\right.$ в вакууме) [19].

Об успешном замещении атомов цинка в наностержнях в процессе гидротермального синтеза в течение $1 \mathrm{~h}$ можно судить по сдвигам энергии связи цинка и кислорода. На спектре остовного уровня цинка наблюдается сдвиг пико в на $0.3 \mathrm{eV}(\mathrm{Zn} 2 p 1 / 2)$ и $0.4 \mathrm{eV}(\mathrm{Zn} 2 p 3 / 2)$ в сторону меньших энергий связи по сравнению с исходными наностержнями оксида цинка. Наблюдается сдвиг пика кислорода кристаллической решетки и кислорода поверхностных гидроксильных групп на 0.4 и $0.8 \mathrm{eV}$ в сторону меньших энергий соответственно (рис. 2,c). Энергия связи пиков на спектре остовного уровня олова $(486.6$ и $495 \mathrm{eV})$, представленном на рис. $3, b$, соответствует $\mathrm{Sn}^{4+}$ [19], положение пиков сдвинуто на $0.6 \mathrm{eV}$ в сторону меньших энергий связи по сравнению с образцом, синтезированным в течение $30 \mathrm{~min}$.

Пример анализа спектров четвертого образца иллюстрирует растворение оксидов и разрушение структуры наностержней, происходящее при синтезе в течение $3 \mathrm{~h}$. Анализ процентного соотношения элементов по данным обзорного спектра показал, что содержание цинка составляет $1.98 \%$. Пиков, соответствующих олову, на спектре не наблюдается. Также в отличие от остальных образцов отчетливо прослеживается пик от кремниевой подложки $(27.47 \%)$, а также азот $(2.05 \%)$, образующийся вследствие разложения мочевины.

\section{Заключение}

Таким образом, рентгеновская фотоэлектронная спектроскопия может эффективно использоваться для контроля и разработки условий оптимизации получения сложных смешанных оксидов в тонкопленочном исполнении для целей современной солнечной энергетики, сенсорики и катализа.

\section{Финансирование работы}

Работа выполнена при поддержке Российского научного фонда (проект № 17-79-20239).

\section{Конфликт интересов}

Авторы заявляют, что у них нет конфликта интересов.

\section{Список литературы}

[1] Gopel W., Hesse J., Zemel J.N. In: Sensors: A Comprehensive Survey / Ed. by Gopel W. VCH, Weinheim. 1991.

[2] Мясников И.А., Сухарев В.Я., Куприянов Л.Ю., Завьялов С.A. Полупроводниковые сенсоры в физикохимических исследованиях. М.: Наука, 1991. 327 с.

[3] Kononova I.E., Vorobiev D.M., Dimitrov D.Tz., Georgieva A.Ts., Moshnikov V.A. // Bulg. Chem. Commun. 2016. Vol. 48. N 2. P. 225-231.

[4] Burmistrov I.N., Varezhnikov A.S., Musatov V.Y., Lashkov A.V., Gorokhovsky A.V., Yudinceva T.I., Sysoev V.V. // IEEE SENSORS - Proceedings. 2015. Vol. 14. P. 7370586.

[5] Chizhov A.S., Rumyantseva M.N., Vasiliev R.B., Filatova D.G., Drozdov K.A., Krylov I.V., Marchevsky A.V., Karakulina O.M., Abakumov A.M., Gaskov A.M. // Thin Solid Films. 2016. Vol. 618. P. 253-262.

[6] Рембеза С.И., Свистова Т.В., Аль-Тамееми В.М., Овсянников С.В., Багнюков К.Н. // Вестник Воронежского гос. тех. ун-та. 2013. Т. 9. № 6-1. С. 95-98. 
[7] Fedorov F., Vasilkov M., Lashkov A., Varezhnikov A., Fuchs D., Kübel C., Bruns M., Sommer M., Sysoev V. // Sci. Reports. 2017. Vol. 7. P. 9732.

[8] Tamaki J., Maekawa T., Miura N., Yamazoe N. // Sens. Act. B. 1992. P. 197-203.

[9] Rumyantseva M.N., Labeau M., Delabouglize G., Ryabova L.I., Kutsenok I., Gaskov A.M. // J. Mater. Chem. 1997. Vol. 7. N 9. P. 1785-1790.

[10] Сычев М.М., Минакова Т.С., Слижсов Ю.Г., Шилова О.А. Кислотно-основные характеристики поверхности твердых тел и управление свойствами материалов и композитов. СПб.: Химиздат, 2016. 276 с.

[11] Божинова А.С., Канева Н.В., Кононова И.Е., Налимова С.С., Сюлейман Ш.А., Папазова К.И., Димитров Д.Ц., Мошников В.А., Теруков Е.И. // ФТП. 2013. Т. 47. Вып. 12. C. 1662-1666. [Bozhinova A.S., Kaneva N.V., Syuleiman S.A., Papazova K.I., Dimitrov D.T., Kononova I.E., Nalimova S.S., Moshnikov V.A., Terukov E.I. // Semiconductors. 2013. Vol. 47. N 12. P. 1636-1640.]

[12] Baruah S., Dutta J. // Sci. Technol. Adv. Mater. 2011. Vol. 12. N 1. P. 013004.

[13] Ko J.H., Kim I.H., Kim D., Lee K.S., Lee T.S., Cheong B., Kim W.M. // Appl. Surf. Sci. 2007. Vol. 253. N 18. P. 7398 7403.

[14] Patil L.A., Pathan I.G., Suryawanshi D.N., Bari A.R., Rane D.S. // Proced. Mater. Sci. 2014. Vol. 6. P. 1557-1565.

[15] Налимова С.С., Максимов А.И., Матюшкин Л.Б., Мошников В.А. // ФХС. 2019. Т. 45. № 4. С. 311-325.

[16] Men H., Gao P., Zhou B., Chen Y., Zhu C., Xiao G., Wang L., Zhang M. // Chem. Commun. 2010. Vol. 46. P. 7581-7583.

[17] Налимова С.С., Мошников В.А., Максимов А.И., Мякин С.В., Казанцева Н.Е. // ФТП. 2013. Т. 47. Вып. 8. C. 1022-1026. [Nalimova S.S., Moshnikov V.A., Maksimov A.I., Mjakin S.V., Kazantseva N.E. // Semiconductors. Vol. 47. N 8. P. 1022-1026.]

[18] Duan J.-F., Hou S.-C., Chen S.-G., Duan H.-G. // Mater. Lett. 2014. Vol. 122. P. 261-264.

[19] Jain V.K., Kumar P., Kumar M., Jain P., Bhandari D., Vijay Y.K. // J. Alloy. Compd. 2011. Vol. 509. P. 3541-3546. 